\title{
CONSIDERAÇÕES SOBRE TRABALHO E INTERAÇÃO NO PENSAMENTO DE HABERMAS
}

\author{
Considerations on work and interaction in Habermas thinking
}

Edilson da Costa $^{1}$

RESUMO: Este artigo apresenta uma reflexão sobre a dimensão filosófica dos conceitos de trabalho e interação em Habermas. Mostra o caráter ambíguo do trabalho enquanto realização e afirmação da especificidade humana e alienação dos sujeitos que trabalham. Traz ainda uma visão positiva do trabalho, pois propõe uma via alternativa para reorganizar os contextos comunicativos de interação de acordo com outros padrões que não os orientados para o agir estratégico.

PALAVRAS-CHAVE: Trabalho; Interação; Ação Comunicativa; Racionalidade; Habermas.

ABSTRACT: This paper presents a reflection on the philosophical dimension of the concepts of work and interaction in Habermas. It shows the ambiguous nature of the work as a realization and affirmation of the human specificity and alienation of the subjects who work. It also brings a positive view of the work, as it proposes an alternative way to reorganize the communicative contexts of interaction according to other standards than those oriented towards strategic action.

KEYWORDS: Work; Interaction; Communicative Action; Rationality; Habermas.

O mundo humano é materialmente construído e culturalmente constituído através do trabalho, e dele a espécie humana não tem como escapar. Ele é, primeiramente, um processo entre homem ${ }^{2}$ e natureza, um processo que possibilita ao homem regular e controlar sua troca de substâncias com a natureza por meio de sua própria ação. Em $O$ Capital, Marx afirma que:

O trabalho é, antes de tudo, um processo entre o homem e a natureza, processo este em que o homem, por sua própria ação, medeia, regula e controla seu metabolismo com a natureza. Ele se confronta com a matéria natural como com uma potência natural [Naturmacht]. A fim de se apropriar da matéria natural de uma forma útil para sua própria vida, ele põe em movimento as forças naturais pertencentes a sua corporeidade: seus braços e pernas, cabeça e mãos. Agindo sobre a natureza externa e modificando-a

\footnotetext{
${ }^{1}$ Doutor em meio ambiente e desenvolvimento pela Universidade Federal do Paraná (UFPR) e professor na Faculdade São Basílio Magno (FASBAM). E-mail: ecofil@uol.com.br

${ }^{2}$ A palavra "homem", com inicial minúscula (e os pronomes pessoais a ela relacionados) fará referência à espécie humana, e não ao gênero.
} 
por meio desse movimento, ele modifica, ao mesmo tempo, sua própria natureza. Ele desenvolve as potências que nela jazem latentes e submete o jogo de suas forças a seu próprio domínio. ${ }^{3}$

No capitalismo avançado, no qual nos encontramos, esse homem não se sente realizado e feliz com sua atividade produtiva. A objetivação do produto do seu trabalho representa, para o trabalhador, a perda do objeto, de tal maneira que ele fica privado dos objetos mais necessários à vida do trabalhador. Assim, o trabalhador passa a se relacionar com o produto do seu trabalho como com um objeto estranho, que adquire vida própria, que ganha poder e domínio sobre o próprio trabalhador, tornando-se uma força hostil e antagônica. Isso é o que o marxismo chama de trabalho alienado: no fato de o trabalho ser externo ao trabalhador, não fazer parte de suas naturezas. O produto de seu trabalho não lhe pertence, mas ganha vida própria enquanto mercadoria e se torna inacessível. Esse trabalho traz junto a sua antítese, sua negação como realização, o seu caráter de exploração e alienação.

Habermas considera válida essa análise feita por Marx, mas lhe faz a crítica de não ter considerado a produção material e a interação social como duas dimensões irredutíveis da prática humana, apenas considerando a segunda uma consequência da primeira. Para Habermas, trabalho e interação são as condições fundamentais para a constituição da espécie humana, as quais determinam as características próprias da nossa existência cultural. O conhecimento, por sua vez, é produto das relações de sujeitos que constroem a sociedade e se autoconstituem como espécie através do trabalho e da interação.

Em sua obra Técnica e ciência como "ideologia”, Habermas ${ }^{4}$ trata do tema trabalho e interação, e aprofunda o conteúdo de cada um dos dois termos. É o conceito de racionalidade que está pressuposto neste desmembramento. Do trabalho resulta uma racionalidade instrumental que, no âmbito da sociedade capitalista, não deixa espaço para uma racionalidade comunicativa, de um tipo de comunicação livre de coerção. Ao contrário, a racionalidade instrumental e estratégica penetra profundamente em todos os setores da vida social e da vida individual. Por isso é preciso pensar o âmbito da interação regido por uma outra forma de racionalidade, a racionalidade comunicativa, que sirva de via alternativa para a superação do predomínio da racionalidade instrumental e da alienação humana.

\footnotetext{
${ }^{3}$ MARX, K. O Capital - Livro I - crítica da economia política: o processo de produção do capital. São Paulo: Boitempo, 2013, p. 188.

${ }^{4}$ HABERMAS, J. Técnica e Ciência como Ideologia. Lisboa: Edições 70, 1997.
} 
O objetivo deste artigo é trazer à tona a discussão habermasiana entre trabalho e interação. Essa compreensão se torna relevante no atual contexto, em que a ciência e a técnica são a ideologia paradigmática de nossa época, onde praticamente não há ciência que não seja conduzida por um interesse e que se percebe que o interesse técnico não deve prevalecer sobre a emancipação, mas ser conduzido pelas ciências sociais críticas, na medida que estas favoreçam a comunicação intersubjetiva.

\section{Trabalho e interação}

Em Técnica e ciência como "ideologia", Habermas afirma que "temos razões suficientes para manter estritamente separados os dois momentos" ${ }^{\prime 5}$ trabalho e interação. Antes de verificar quais são essas razões, é importante examinar o conteúdo desses dois conceitos.

Ao referir-se ao enfoque crítico de Habermas, Araújo diz que:

Habermas parte da distinção entre trabalho e interação. Trabalho é toda atividade instrumental direcionada a um fim, obedecendo a regras técnicas que se fundam num saber empírico. Comporta ainda uma escolha racional com relação a fins. Já a atividade de comunicação/interação vem mediatizada por símbolos e se conforma às normas em vigor. ${ }^{6}$

Assim, sob o conceito de trabalho Habermas tematiza questões relativas ao domínio técnico tanto do entorno natural quanto do social, e acredita que pelo trabalho se conquista cientificamente a natureza e o homem. Sob o conceito de interação, ele tematiza questões relativas ao convívio social entre indivíduos que se comunicam entre si, ou seja, relações morais.

O trabalho (ou ação-racional-com-respeito-a-fins) é regido por regras técnicas que tenham sua eficácia comprovada empiricamente. A racionalidade dos meios exige um saber empírico tecnicamente utilizável que, dentro de um contexto social significa aumento das forças produtivas, uma implementação de saber pleno de consequências sociais, como capacitação e qualificação técnica da força de trabalho existente.

A interação social é regida por normas consensuais que definem expectativas recíprocas; funda-se na intersubjetividade e no entendimento mútuo e está embasada no reconhecimento geral das obrigações. O que sustenta a interação ou agir comunicativo é

\footnotetext{
${ }^{5}$ Id. Técnica e Ciência como Ideologia. Lisboa: Edições 70, 1997, p. 42.

${ }^{6}$ ARAÚJO, Inês L. Introdução à filosofia da ciência. 2. ed. Curitiba: Editora UFPR, 1998, p. 187.
} 
o respeito às normas intersubjetivamente válidas. Dessa maneira, o agir comunicativo não pode ser racionalizado sob o aspecto prático-moral da capacidade de entendimento do sujeito de ação, bem como da possibilidade de justificação das normas de ação.

O que leva Habermas a fazer essa distinção entre trabalho e interação é o conceito de razão. Ele é um autor que se insere na linha do projeto inacabado da modernidade, ou seja, ele ainda acredita no potencial do projeto do esclarecimento como um processo de argumentação voltado para a tarefa de mediação entre razão e não razão, entre a razão e a esfera do poder, da dominação. Habermas ${ }^{7}$ entende a razão como um "a priori” que fundamenta e determina a condição humana, sua existência social e sua evolução.

Para o autor, a função da filosofia é pensar a razão: “...el pensamiento filosofico nace de la reflexivización de la razón encarnada en el conocimiento, en el habla y en las acciones. El tema fundamental de la filosofía es la razón" $"$. A filosofia deve contribuir para o progresso da espécie humana rumo à maioridade e à emancipação. Nesse sentido, Habermas permanece fiel à tradição filosófica ocidental, construindo sua teoria na ideia da emancipação do homem através do esclarecimento e da formação racional da identidade dos sujeitos humanos e das coletividades. Essa razão a que Habermas se refere e que orienta toda a sua reflexão não é qualquer modelo de racionalidade, mas uma razão crítica, libertadora e emancipatória.

O interesse pela emancipação é inerente à razão. Habermas ${ }^{9}$ assimilou de Kant o princípio de que a ideia de razão já inclui a vontade de ser racional, a vontade de alcançar a emancipação, a autonomia e a responsabilidade da direção da própria vida. Mas, além desses interesses, a razão apresenta outros interesses.

\section{A compreensão do termo interesse}

Os interesses da racionalidade humana, segundo Araújo ${ }^{10}$, podem ser classificados em três grupos básicos. As ciências empírico-analíticas têm interesse pelo controle dos fenômenos naturais e pela autonomia frente à natureza, que Habermas chama de interesse técnico. As ciências histórico-hermenêuticas têm interesse pelo asseguramento e expansão do entendimento mútuo e autoentendimento na organização das relações sociais

\footnotetext{
${ }^{7}$ HABERMAS, J. Op. cit., nota 3, p. 21

${ }^{8}$ Id. Teoria de la acción comunicativa. Racionalidad de la acción y racionalización social. Tomo I. Madrid: Taurus, 1987, p. 14.

${ }^{9}$ HABERMAS, Op. cit., nota 3, p. 21.

${ }^{10}$ ARAÚJO, Op. cit., nota 5, p. 192.
} 
e da própria vida; é o interesse prático. As ciências sociais críticas têm interesse pela emancipação e seu modo de investigação é a reflexão crítica.

O interesse técnico orienta o conhecimento de acordo com as condições do agir instrumental, ou seja, do trabalho, buscando uma disponibilidade e um controle tecnicamente possível dos processos naturais. O conhecimento orientado pelo interesse prático, próprio das ciências do espírito, se processa na dimensão da interação, através de formas correntes de comunicação e intersubjetividade. O objetivo é assegurar um entendimento recíproco entre diferentes indivíduos, grupos e até civilizações.

O interesse da razão pela emancipação é um interesse derivado: ele é dependente dos interesses que orientam a intersubjetividade e controlam a disponibilidade técnica. É mediatizado por símbolos e adere às condições do agir instrumental. Portanto, o interesse emancipatório assume a forma de interesse inerente ao conhecimento prático e técnico.

Essa teoria habermasiana dos interesses deixa claro que o processo formativo da espécie humana é dependente das condições da natureza subjetiva bem como da natureza objetiva. As condições fundamentais da autoconstituição e reprodução da espécie são orientadas pelo trabalho e pela interação. Estas orientações fundamentais não visam a satisfazer necessidades imediatas, mas solucionar problemas sistêmicos relacionados com a conservação da vida e que só podem ser avaliados no decurso da existência cultural da espécie humana.

\section{Ação instrumental e Ação comunicativa}

Habermas faz uma diferenciação entre emancipação frente à natureza exterior e emancipação frente às formas de dominação social. Por isso, ele distingue dois tipos de ação social: o agir instrumental e o agir comunicativo. $\mathrm{O}$ agir instrumental corresponde ao interesse técnico em dominar a natureza e o agir comunicativo corresponde ao interesse prático voltado para a superação das formas de dominação social e política e estruturação de uma interação racionalmente motivada. Não se deve identificar emancipação política e progresso técnico.

Para Habermas é de suma importância manter rigorosamente separados os dois momentos, trabalho e interação, para que se possa propor uma via alternativa à forte tendência de reorganizar os contextos comunicativos de interações de acordo com os padrões de sistemas orientados para a ação-racional-com-respeito-a-fins. Ele aponta, ainda, que um sujeito, mesmo enquanto tomado como objeto de uma ação instrumental, 
conserva sempre a capacidade para "relações comunicativas", e segue sendo sempre um aliado ou um rival em potencial no jogo da interação. Evidentemente, as relações humanas podem resultar estruturadas cada vez mais como relações de controle racional-científico, como também, podem estruturar-se com base na "complementaridade", na "reciprocidade" e no "reconhecimento mútuo".

Na sociedade industrialmente evoluída, a dominação política assume uma nova forma, ela tende a perder seu caráter explorados e opressivo e a tornar-se "racional", sem que com isso desapareça. Esta forma de dominação política permanece camuflada porque o crescimento institucionalizado das forças produtivas, fruto do progresso técnico e científico, legitima este modelo de sistema social. Neste ponto, Habermas ${ }^{11}$ recorre aos argumentos de Marcuse. Para este autor, a intrínseca relação entre razão técnica e dominação mostra que aquilo que Max Weber chamava de "racionalização" dissemina não a racionalidade como tal, mas, em seu nome, uma determinada forma inconfessada de dominação política.

Habermas, citando Marcuse, diz que a repressão, objetivada na "sujeição intensificada dos indivíduos ao imenso aparelho de produção e de distribuição, na desprivatização do tempo livre, na quase indiferenciável fusão do trabalho social produtivo e destrutivo"12 tende a desaparecer da consciência dos indivíduos pois está legitimada na crescente produtividade e domínio da natureza, que ao mesmo tempo provê o sustento dos indivíduos, amplia as comodidades da vida e aumenta a produtividade do trabalho.

Entretanto, o problema mesmo não é a razão técnica como tal, mas a sua universalização, a perda de um conceito mais amplo de razão, em favor da validez exclusiva do pensamento científico e técnico, a redução da praxis a techne, e a extensão da racionalidade instrumental a todas as esferas de decisão. Consequentemente, uma ruptura radical com a razão técnica não resolve o problema. É preciso, antes, situá-la dentro de uma teoria compreensiva da racionalidade. É por isso que Habermas decompõe o conceito marxista de "atividade humana sensível" em dois componentes: trabalho ou ação-racional-com-respeito-a-fins e interação social ou ação comunicativa. Os sistemas sociais estendem seu controle sobre a natureza externa com ajuda das forças de produção. Para isso precisam de conhecimentos tecnicamente utilizáveis que necessariamente incorporam supostos empíricos, os quais comportam uma pretensão de verdade. A natureza interna de cada indivíduo se adapta à sociedade com ajuda de estruturas

${ }^{11}$ HABERMAS, J. Op. cit., nota 3, p. 47-48

12 Ibid, p. 47. 
normativas nas quais são interpretadas as necessidades e nas quais as ações se convertem em proibidas, permitidas e obrigatórias.

Tais normas requerem uma justificação. Somente sobre a base de uma distinção entre trabalho segundo regras técnicas e interação segundo normas válidas podemos reconstruir o desenvolvimento da espécie humana como um processo histórico, ao mesmo tempo, de desenvolvimento técnico e, interdependentemente, de desenvolvimento institucional e cultural. Não se deve identificar emancipação política e progresso técnico. Mesmo porque, a racionalização na dimensão do agir instrumental significa crescimento das forças produtivas e expansão do controle técnico, enquanto a racionalização na dimensão da interação social deve conduzir a uma comunicação livre de coerção.

\section{Conclusão}

No pensamento habermasiano a emancipação não se dá como resultado direto dos processos de produção, mas das ações voltadas para o entendimento mútuo. Esse entendimento não é mensurável, ele é sempre um projeto, e vai sendo construído nas relações interpessoais. Na distinção que Habermas faz entre trabalho e interação pode-se perceber que os mecanismos repressivos e opressivos presentes na dimensão do trabalho penetram profundamente em todas as relações humanas. Esses mecanismos vão sendo reproduzidos para as novas gerações, na família e em outras instituições sociais, por meio da linguagem e dos símbolos, e isso acontece bem antes que o indivíduo entre para o mundo do trabalho.

Essa situação, ao invés de levar a um pessimismo filosófico, faz com que Habermas tenha uma visão positiva: ele acredita que, a partir desta separação entre trabalho e interação se pode propor uma via alternativa para reorganizar os contextos comunicativos de interação de acordo com outros padrões que não os orientados para o agir estratégico.

\section{Referências}

ARAÚJO, Inês L. Introdução à filosofia da ciência. 2. ed. Curitiba: Editora UFPR, 1998. HABERMAS, J. Técnica e Ciência como Ideologia. Lisboa: Edições 70, 1997.

HABERMAS, J. Teoria de la acción comunicativa. Racionalidad de la acción y racionalización social. Tomo I. Madrid: Taurus, 1987. 